\title{
n-1. Making Multiplicity: A Philosophical Manifesto
}

\section{Gerald Raunig 1}

Occupation without subject. Movement without subject. Asubjective composition. The occupation movements of the last years have been characterised by their dispensing with any subject. No unity, no wholeness, no identifiable class. Classical theories of revolution would see this as a problem, the (revolutionary) subject being a condition for the possibility of revolt, insurgency, revolution as a fixed component of a theory of stages: only once a uniform subject appears on the horizon, a molar block, the working class, a united front, only then - seen from this angle-can the revolution get going.

And yet, the absence of the subject does not have to be interpreted as a deficiency. Quite the opposite, it could indicate a new quality in the revolution, in a henceforth molecular revolution, and the primacy of multiplicity within it. When the subject is missing, it has not just gone amiss, as a gap (still) gaping and begging to get closed. In view of the composition of the molecular revolution there is no need for unification, or for the representation of a unified (class) subject by leaders, party and vanguard. The rejection of the primacy of the class, or of a specific class (be it the proletariat, or a middle class threatened by decline), does not in any way imply tuning out the hierarchising differentiation that takes place more radically than ever in current capitalist production. Differential capitalism striates the differences, hierarchises and valourises them. And yet molecular multiplicity raises no hopes in any of the imaginings of resistance against this machinic-differentiating capitalism that undertake to homogenise and totalise differences. Even in their negative manifestation there is no way back ahead of multiplicity, but only its dis/continuous unfolding. 
But even the subject, the one, the whole, where it is no longer absent, is not the consequence of a process of collecting, forming, unifying the many, the singular, the dispersed, to be composed into a molar block. It does not follow a logic of addition, but one of subtraction. It must first be extracted from the uncountable multiplicity, detached, dis-counted in order to be one. The one emerges only when the logic of counting, classifying and identifying lays its grids on the multiplicity; when the uncountable is domesticated in the process of counting.

The subject can appear only through subtraction from the multiple. $n-1$.

\section{Radical inclusion and molecular organisation}

The Occupy movement, and before it the Spanish 15-M movement and in some respect also the North African revolutions that have come to be labelled uniformly as 'Arab Spring', have doubtlessly been pervaded by genealogical lines of earlier movements and uprisings. The practice of occupation played as much a recurring role as the critique of representation and the invention of new interweavings of dispersion and assembly. The amphibian paths of the revolutionary machines nowadays no longer need a durable mole burrow in order to dig their way through the world and to make their appearance here and there, in different geopolitical situations, in a new-old guise. They do not even need the form of the snake that time and time again makes its way in all directions without digging a fixed system of burrows, without limiting itself to any given element on earth and without leaving any traces. The floating narratives, forms of action and bundles of affects of the occupation movements are social-machinic assemblages, and thus continuity and discontinuity, repetition and difference, resumption and invention concatenate in them without transition.

There is no linear relation between the different occupation movements of 2011 and earlier movements. The US-American Occupy movement borrowed from the gestural techniques of the Social Forum as much as from old anarchist modes of action and grassroots forms of assembly, from the waves of university occupations since 2008 , as well as 
from the practice of occupying the Tahrir Square in Cairo. Conversely Egyptian activists adopted aspects of the people's mic developed in the Occupy movement. This is not a linear relation that might postulate an origin here or there. There are only similarities, singular recurrence and implicit and explicit references, processes of translation in all directions and productive mistranslations in all dimensions.

In the context of this simultaneous disjunction and conjunction the occupation movements have successfully left behind constitutive identifications and escaped old and solidified categories. Time and time again they traverse the dichotomous segregations in violent and nonviolent, revolutionary and reformist, intellectual and mass, young and old, majorities and minorities, political, apolitical and antipolitical. What counts is the affection in the interstices between these dissimilar pairs, common action taking account of the dangers for the precarious bodies, the practice of radical inclusion.

Radical inclusion is by no means the indiscriminate, farcical repetition of a hippie dream, a romantic projection of the suspension of class boundaries and national borders, the fantasy of painless fraternisation. At the same time the concept does not draw the simple picture of an open door (as in 'leaving the door ajar'), of letting someone into a room and engaging with the one thus admitted, of a possible integration into an already existing territory. Radical inclusion means rather the potentiality of openness of existential territory itself, of a fundamentally inclusive territory without doors or thresholds, not surrounded or traversed from the outset by borders, an inclusive mode of reterritorialisation of space and time. This implies not only the absence of a social preformation of the territory, but also the impossibility of linear-strategic planning, the unpredictability, the social and organisational openness of molecular reterritorialisation.

The reterritorialisation in question applies not to space alone. What shapes the modes of action of the protesters is also a reappropriation of time. The occupiers take seriously the space and time that they establish. They take their time for long, patient discussions, take time to stay on-site and develop a new day-to-day life. In an otherwise boundless life 
they spread out short new durations of daily life. This is no exit, no disengaging from the world, not an out-time but a breach in the time regime of subservient deterritorialisation. It is no longer a struggle for a mere reduction of working time, but an entirely new striation of time as a whole. In machinic capitalism the stake is to have it all - the totality of time, its appropriation as a whole. In the midst of the nervous polyrhythmicity of precarious life, a surplus is invented-and in the midst of all this subservience, a desire is produced not to be co-opted. In the middle of a rushed timelessness the precarious occupiers apply different time relations, striate time in the patience of the assemblies, in the spreading of life, dwelling, sleeping onto the squares.

Radical inclusion means to sustain and affirm the differences, and within them continuously to differentiate, multiply, in a continuous expansion of multiplicity: difference between the differentially hierarchised precarious, difference between different groups of homeless, people threatened by homelessness and those fighting for their right to a place to live, difference of the militant modes of expression between younger and older generations, difference between those who can be physically present at an assembly and those who cannot, whose presence however is made possible by a post-media ecology of live streams, tweets and social networks.

Radical inclusion in no way implies allowing any reterritorialisation in the form of racisms or sexisms. On the contrary, multiplicity is to propose a form that will deprive any discriminatory identification of its breeding ground. This does not, however, make it an absolute deterritorialisation in which every reterritorialisation, all the way to attempts at organising, would remain barred. It is rather a case of molecular forms of organisation, of instituting ever-new existential territories that are able to counter the closures. Instead of accepting the molar organisational narratives of revolutionary history (and its structuralising historiography) as the only one possible and to reproduce it to infinity, there is a need for invention, innovation and multiplication of revolutionary practices and narratives. Then the one great event turns into an unending chain of instituent practices, the overtaking of the state apparatus into a consolidation of constituent power, the 
institutionalisation of the revolution into the invention of ever-new monster institutions, institutions of the common.

Molar organisation arises as a striating reterritorialisation. It focuses the struggles on a main issue, a principal contradiction, a master. In a molecular world of multiplicity, dispersion and multitude, a new form of reterritorialisation is called for, a molecular and inclusive reterritorialisation beyond individual or collective privileges. It does not pursue particular goals, does not establish privileges to then secure them. It is the privileges of each singularity taken by itself that defy all individual and collective privileges. But these privileges exist only where each singularity can live out its own strangeness to the extent of its possibilities, and experiment with its own form of concatenation. No privileged position for intellectuals, for party apparatchiks, artists, the black block or professional revolutionaries. Exclusivity for all. Molecular struggles are struggles that emerge accidentally and continue to spread through what is accidental to the accidentals. No master heads the molecular organisation.

Multitude, dispersion, multiplicity have quite evidently become part of the contemporary modes of production of post-Fordist capitalism, of current ways of living, and yet they can hardly be found in forms of political organising. The multitude has become the technical composition of postFordist production, but to a much lesser extent its political composition. On the contrary, existing forms of political composition seem rather to prevent a non-identitarian composition in a dispersed multiplicity than to foster it. Trade unions, political parties and other traditional institutions in their rigid, structuralised form often constitute impediments to the imagination and invention of a molecular political organisation.

In the 1990 and 2000 decentralised, polycentric, molecular modes of organisation remained limited to tiny fractions of social movements. From Zapatism to Reclaim the Streets, from the critique of globalisation to the Argentinian Piqueteros, from the noborder network to queer-feminist actions and to the Euromayday movement, practices taking a critical stand on representation have multiplied, but a massive, monstrous, viral spread of molecularity has failed to set 
in. While at the level of the modes of production dispersion, multiplicity and cooperation have imposed themselves as a form of 'communism of capital', multiplicity has remained marginal in political organisation.

Sure, the multitude has been invoked for more than a decade now. 'In truth, it is not enough to say, "Long live the multiple", difficult as it is to raise that cry ... The multiple must be made."2 This admonition by Gilles Deleuze and Félix Guattari seems now, more than thirty years after it was published, to flow like multiplicity itself over the thresholds of perceptibility of micropolitical endeavours - 'with the number of dimensions one already has available - always $n-1{ }^{\prime}{ }^{3} n-1$, the formula for multiplicity from A Thousand Plateaus, seems to have been realised more broadly than ever in the occupations and assemblies of the last years, increasingly since the beginning of 2011, with their inventive techniques that indeed 'make the multiple'.

The human microphone: neither human nor microphone Besides its modes of assembly and of occupation, the Occupy movement's most talked about practice is likely the human microphone (or people's mic). Its use emerged in September 2011 as if by accident and, as it were, out of the adversity of the legal situation at Zuccotti Park. It then very quickly developed far beyond the initial occupation in Manhattan and was further refined.

The specific first place of the Wall Street occupation, whose old name was Liberty Plaza, embodies the current paradox of blurring the public and private, being a public square in private hands. The empty promise of the 'public space' was here taken literally. Public space does not exist-certainly not in the smooth spaces of the urban centres, be it the touristic non-place of the Puerta del Sol, be it the privatised sphere of Zuccotti Park, be it the density of the traffic at Tahrir Square. And yet - or maybe precisely because of this - the new activisms occupy central squares, turn them into common-places as a paradoxical provocation of normativity and normalisation.

Zuccotti Park is special insofar as it is a public square in private hands. In these circumstances the use of microphones, 
megaphones or PA systems within it was prohibited by police order. This is why in larger general assemblies the occupiers started to repeat in unison every sentence by the speaker. The functionality of this repetition initially lay in making a speech intelligible even to hundreds of people in an open-air setting.

From a distance this procedure of 'amplifying' looks like a priestly technique (see, for example, YouTube videos of the process). Here the hoarse voice of the prayer leader, there the enthusiastic affirmation of the congregation. Between shepherd and flock it is a pastoral relation between the government of the whole and the individuals-omnes et singulatim. Singularities are in danger of drowning in this process that is both homogenising and individualising. The more sentences the crowd repeats, the more the content, the meaning and the appropriation of the statements are relegated to the background. While some seem to fall into trance precisely through the pastoral (self-) relation, for others their exhaustion brings about a certain automation. The mechanical reproduction of the language material neatly divided into portions can be seen as the rehearsing of (self-) subjugation.

If one looked at the human microphone from this perspective only, one would have to understand it as a technique of centralisation, homogenisation and unification of the multiple. But is it not rather the case 'that this kind of machinic multiplicity, assemblage, or society rejects any centralising or unifying automaton as an "asocial intrusion". Under these conditions, $\mathrm{n}$ is in fact always $\mathrm{n}-1 .{ }^{4}$ In this second meaning of minus in $\mathrm{n}-1$ the question is no longer only that the one does not preexist the multiple, that it has not always already been part of the multiple, that it emerges only in and out of subtraction. The one, unity, unification is not only a by-product of the introduction of a grid of countability - it is actively rejected by the machinic multiple. The molecular crowd, the multiple, turns away the 'asocial intrusion' of the one, attacks the one. It does not permit the transformation of the uncountable into the matrix of counting.

Seen from this angle the potentiality of the human microphone as an offensive form for the multitude and polyphony can be emphasised, in which the chorus as amplification cannot be reduced to a euphoric or automatic affirmation of 
the speakers. In this respect, however, the human microphone is neither 'human' nor 'microphone'. It is not a microphone because it does not rely on variations in voltage to render a source as faithfully as possible while suppressing background noise. Rather, it facilitates the multiple, the multiplication of voices, and at the same time it produces 'background noise' instead of suppressing it. The purpose is then not (only) to render linguistic material as accurately as possible, not a pure reproduction of linguistic content, but rather a continual unfolding of the enunciation.

The human microphone lacks not only the central characteristics of a microphone-it is also not 'human'. Emphasising humanness would lose sight of social-machinic relations out of which the enunciations of the multiple emerge. The multiplication of voices modulates the spoken content to a polyvocal murmur. At first it is surely the many voices that make an effort at amplifying one voice. But the question is not just of the voices of distinct individuals compounding to an understandable and linguistically as unequivocal chorus as possible. It is also of the blurring of author and audience, on the backdrop of a new schizo-competency, an inventive, machinic subjectivity that ultimately engenders multitasking between reception, repetition and enunciation of one's own position. As in the day-to-day post-Fordist production, traversed by all sorts of polyphonic, polyvocal and polyaffective lines, there is quite a disarray, in which all happens at the same time. We can concurrently hear, repeat and take a stand.

The one never enters into an exchange with the multiple as unity, as identity. The one as a whole is only ever subtracted. There is a relation between the multiple and the one only when the one appears as a singular that is then no longer subtracted from the infinite-multiple. Singularities interact with the multiple as components of a monstrous com-position in which the single voices produce polyphony not by concurring, but by being attuned each in their own way. This applies also to the practice of the micro-amplification of the human microphone.

It can happen that the chorus whose voices speak the same turns out to be radically polyvocal and differentiated. One voice supports the speaker with gestures of the hands, another 
expresses its dissensus with other gestures even as it repeats the last sentence of the speaker, while the third has turned away from the speaker in order better to fulfill its amplifying function for the bystanders.

Becoming-many: spreading in all dimensions, uncountable In the course of the expansion of the Occupy movement the process of the human microphone was applied to ever larger assemblies, in several consecutive waves of repetition, up to five of them, a truly massive amplification. Even in the moving mass rally the new practice of the mic check found its spontaneous use in Manhattan. But it would be wrong to explain the emergence and spread of multiplicity in the logic of counting by addition and quantitative increase. Multiplicity is not made 'by always adding a higher dimension, but rather in the simplest of ways, by dint of sobriety, with the number of dimensions one already has available - always $n-1^{\prime} .{ }^{5}$ The foundation of the production of multiplicity lies just as much in overcoming the additive logic of counting (up) as in rejecting the one, which emerges only in the (dis-)counting from the multiplicity.

One of the most important mouthpieces of the Occupy movement was a New York-based magazine by the name of $n+1$. It arose from the old necessity of political engagement of intellectuals and has attempted since 2004 to link cultural and literature critique with topical questions on the 'intellectual situation'. In 2011 the publishers of the magazine also issued several semi-regular issues of the newspaper occupy. With the involvement of cultural criticism in activist practices $n+1$ has doubtlessly contributed to the diversity of the New York occupation movement. But in terms of making multiplicity, the practice and title of the magazine, $n+1$, are problematic. Just like the magazine cannot do without the classic centrality of the intellectual in the grid of representation, it remains caught in conventional thinking about the spread and concatenation of experience, knowledge and intellect. Against all the experience of instrumentalisation of media intellectuals as a function of the mass media they continue fostering the idea of intellectuals as the source of knowledge and the media as a means of transporting this knowledge to the masses. 
With the code $n+1$ a false multiplicity is constructed, a 'multiplicity' in the logic of countability, whose propagation functions in terms of the addition of units. Such a logic developing in $n+1$ derives from the figure one, and one can be added to it. Multiplicity however is precisely not made up of units, but consists in singular dimensions that spread in movable directions. Singularities and multiplicity, components and composition are then co-emergent, equiprimordial or entirely without origin, while units emerge only once discounted from the multiplicity by subtraction. Just like the multiple 'has' no subject, it also has no object.

The occupation movements seize on the experience of a critique of representation and of non-representational practices of the last decades. They invented the slogan 'Occupy everything! Demand nothing!' and make no demands, even as the representatives of representation in politics and media demand this of them ever more insistently. They turn against all forms of representation, including the primacy of the face and the name. They have opted for remaining faceless, rather a multiplicity of faces, not to establish intellectuals as voices of the movement, rather a transversal intellect, not to produce visibility in the mainstream media, rather a multiple visibility in the many forms of post-media ecology.

With all this, the problem of propagation remains, and with it the old question: how can there be more of us? But the question is put wrong to begin with. Starting out with a 'we', we always end up with the question of majority. Being-more in the sense of a majority is the wishful thinking and target point of a linear imagining of propagation via sender and receiver, knowledge production and reception, representatives and represented. It is only by turning from the question of majority and being-more to that of becoming-many that the dominant logic of the $n+1$ can be transformed into a rejection of identification and representation, into $n-1$.

Becoming-many always takes place in the dimensions of the multiple. The majority has no role to play in these dimensions. And even the 99 per cent do not constitute a majority here, not even those 146 per cent the Moscow philosopher Alexei Penzin ironically wrote about in connection with the Russian election fraud in December of 2011, which turned the 
frail fledgling of Occupy Moscow into a veritable social movement. In a post-media ecology multiplication and propagation is not to be understood as the addition of one to another, but mainly in the mode of machinic-monstrous contagion. This is where the media lose their quality as the centre in a linear process of representation from production to reception. The middle is the multiple itself. From it the multiple grows and spreads. It is no longer a question of target-group objects to be 'addressed' through mass media with the greatest possible outreach and their author-subjects, but that of the production of a completely different middle here and now, the rampant torrent in the middle of the multiple. Media are not just a means here. They take part in the production of sociality and become in a new sense social media. These forms of social media defy any simple instrumentalising as a coupling between active and passive, between production and reception. Think of the praxis in Cairo by which a multitude of video activists placed their pictures on YouTube and other web channels, and these clips were then brought back as screenings to Tahrir Square and later into many decentralised places in Cairo. The multifaceted video production and presentation goes beyond the purely defensive technique of documenting police assaults and state repression, and becomes a multiperspective production of images and sounds, a process of production of the social. Or think of the live streams from the assemblies since the university occupations, from the asambleas and general assemblies. They become a revolutionary reality TV and create despite all the triviality, often even ridiculousness of the picture of banal discussion processes, a new idea of transparency of the political.

Post-media sociality emerges in the various forms of the production of expression, not in the separation of virtual/media and real/corporeal. The precarious bodies on the occupied squares, the human microphone, the live streams and social networks are components of one and the same make-up, just as media, im-media(te), post-media as they are real. Body machines, social machines and technology machines interlink in entirely different ways than in the socio-narcissistic hustle and bustle of Facebook and co. 


\section{Post-media sociality: $\mathrm{n}-1$ vs Facebook revolution}

A new quality in the trade of product marketing has been reached, as products no longer need to be praised and sold as revolution by $\mathrm{PR}$ companies, but by the revolution itself, from within it. Facebook was fortunate enough to make this experience as the Arab revolutions were being marketed as Facebook revolutions.

Besides being a media tool for revolutions, a means of self-representation, communication and manic exposure of life, Facebook is primarily the undeletable storage of millions of private data sets, a business model for the exploitation of unwaged labour, a medium for selling data primarily for the economic goals of others, a medium of forced confessions, of coercion to 'de-privatise'. This coercion relies on the yearning towards the light of virtual sociality, on the urgency of visibility that comes along with a new imagining of privacy as deficient. Indeed the concept of the private has always carried in itself a deficiency, a lack, a being-deprived. In antiquity it was a lack of office, a lack of public view, a lack of opportunities to act politically. However, in the sociality of contemporary social media, privacy becomes a problem because it implies invisibility, economic imperceptibility and a decoupling from the lifeblood of the social networks.

One could take this problem seriously and in this respect forcibly enact at all levels a practice of resistance based on a radically affirmative strategy of deprivatisation, publicising, becoming-public. But one could also, conversely, say that an offensive becoming-invisible, becoming-imperceptible, decoupling represents a much-needed mode of subjectivation, a form of desertion from the socio-narcissistic frameworks of our times. There is probably a need for the invention of forms of vacillating, of concatenating, of traversing these two models.

In any event it is not appropriate to the post-media situation to fall back on prevalent and linear conceptualisations of the relation between sociality and media that conceive of the former being induced by the latter. Surely the 'Arab Spring' was not simply induced by the media, just like the occupation of squares and assemblies of 2011 were not alone responsible for the boom of social media that year. In this sense not much remains of concepts like 'the Facebook revolution' besides the 
above-mentioned marketing aspect on the one hand, and the crudely pragmatic aspect of the instrumentalising of Facebook and Twitter for purposes of mobilisation on the other, as tactical theft of capitalistically marked media. Both interpretations fail to account for the quality of the social-machinic make-up that characterises post-media sociality today.

This social-machinic quality has no subject, no object: it develops in the entanglement of media and sociality, in the tumultuous middle of the multiple. It needs self-organised networks and their social, free software, which explore new paths both technically and at the level of organisation. Such a network has been in existence for the Spanish-speaking spaces for about four years, under the name, hard to believe, $n-1$, at the address n-1.cc. A techno-political dispositif that aims at radically extending the possibilities of media and sociality, in a self-organised way, horizontally, for and from the bases. From the perspective of $n-1$ counter-information, activist research and dissident knowledge production require a different quality of data protection, but also different technical principles of social interaction. This means at the same time greater privacy and tools for social exchange, more selfcontrol over one's own data and greater technical reliability than the commercial providers of the Web 2.0 could offer.

Created as a new social network by hackers and political activists, $n-1$ first aims to enable an exodus from the narcissistic circles of Facebook. The closed system of Facebook with its techniques of dividualising desire is to be evacuated. Admittedly, exodus does not here mean a total rejection. Many of the activists use $n-1$ for political exchange and at the same time continue to have a Facebook account for personal communication. The broad viral mobilisation for $15-\mathrm{M}$ between February and May 2011 was achieved largely via Facebook, Twitter and Youtube. $n-1$ as a new network remained for years no more than an insider tip. With $15^{-M}$ and the movement 'democracia real ya!' this changed abruptly. Albeit even now $n-1$ does not reach the membership levels of Facebook, but in the course of 2011 the number of users rose to more than forty thousand. The word is out. In an intermediary position between self-determined publishing and just as self-determined practices of becoming-invisible it is possible 
to develop a different sociality than in the socio-narcissistic networks structured by economic interests.

Post-media sociality arises precisely in the non-linear, mixed practices between squares, streets, assemblies and media spaces. Connecting to many machines does not necessarily mean being dependent on them. Sociality arises precisely in the interstices of social, media and body machines. Making the multiple means to concatenate these machines instead of hooking them up to the apparatuses of the one. Rejection of the molar block, rejection of the united front, rejection of the counting/subtracting and of the unified subject. $n-1$.

\section{Notes}

$1 \quad$ Translated by Alain Kessi.

I would like to thank Raúl Sánchez Cedillo, Marcelo Expósito, Montserrat Galcerán and Isabell Lorey for lively discussions, Anna Frei, Sandra Lang and Rastko Močnik for important hints as well as Christoph Brunner and Roberto Nigro for the shared development of some preliminary work for this text. Gilles Deleuze and Félix Guattari, A Thousand Plateaus: Capitalism and Schizophrenia, trans. Brian Massumi (Minneapolis: University of Minnesota Press, 1987), 6.

3 Ibid.

4 Ibid., 17.

5 Ibid., 6. 